\title{
The Influence of Fiber Length and Concentration on the Physical Properties of Wheat Husk Fibers Rubber Composites
}

\author{
Maged S. Sobhy ${ }^{1,2}$ and M. T. Tammam ${ }^{2,3}$ \\ ${ }^{1}$ Physics Department, Faculty of Science, AL-Baha University, 65431, P.O. 1034, AL-Baha, Saudi Arabia \\ ${ }^{2}$ Polymer Physics Laboratory, Physics Department, Faculty of Science, Beni-Suef University, Beni-Suef, Egypt \\ ${ }^{3}$ Physics Department, Faculty of Arts and Science, Egdabia Branch, University of Gar-Younis, Benghazi, Libya
}

Correspondence should be addressed to Maged S. Sobhy, ms_sobhy60@yahoo.com

Received 28 October 2009; Revised 6 March 2010; Accepted 22 April 2010

Academic Editor: Hj Din Rozman

Copyright (c) 2010 M. S. Sobhy and M. T. Tammam. This is an open access article distributed under the Creative Commons Attribution License, which permits unrestricted use, distribution, and reproduction in any medium, provided the original work is properly cited.

Ethylene-propylene-diene terpolymer (EPDM)/wheat husk fibers (WHFs) composites were prepared using a laboratory size tworoll mill. Cure characteristics and some physical properties such as swelling, mechanical, and thermal properties of the vulcanizates were studied. The adhesion status between the WHF and rubber matrix is lacked in general, but it started to reinforce the matrix at higher WHF contents where a higher restriction to molecular motion of the macromolecules with uniformed stress distribution of the fibers is produced. From the TGA analysis, a thermally stable property is exhibited, which in turn partially enhanced the reinforcement of the WHF-EPDM composites due to the natural adhesion during vulcanization.

\section{Introduction}

Natural fibers are subdivided based on their origins, coming from plants, animals, or minerals. Natural Plant-fibers are grouped into four types: seed hairs (cotton, kapok), bastfibers (flax, hemp, jute, ramie), leaf-fibers (sisal, henequen, coir, abaca), and wood flour (wheat husk, rice husk) [1-5]. It is well known that wheat husk fibers were employed in Egypt [1] for a very long time ago for buildings as construction materials mixed with clay. Generally, the different types of natural fibers are used to reinforce plastics (thermosets as well as thermoplastics) and reach the mechanical properties of glass-fiber composites, and they are already applied, for example, in automobile and furniture industries due to their relative high strength and stiffness and low density [5].

Composites can be tailored to have the desired properties by incorporating particulate fillers into a polymer matrix to suit different applications [6]. For economic and environmental reasons $[7,8]$, there is an increasing use of polymer composites filled with lignocellulosic materials such as wood flour, rice husk, wheat husk, jute, and sisal [9-12].

The main disadvantage encountered during the incorporation of natural lignocellulosic materials into polymers is the lack of good interfacial adhesion between the two components, especially in the case of rubbers, due to the incompatibility of hydrophilic natural fibers that are to be used as reinforcement with hydrophobic polymer matrix $[13,14]$.

Furthermore, these composites are often associated with agglomeration as a result of insufficient dispersion, caused by the tendency of fillers to also form hydrogen bonds with each other during processing [13-15]. Moreover, the polar hydroxyl groups on the surface of the lignocellulosic materials have difficulty in forming a well-bonded interface with a nonpolar matrix, as the hydrogen bonds tend to prevent the wetting of the filler surfaces [14-16].

Many authors [6, 9-12, 17-21] have carried out their studies in this area. They had indicated that the incorporation of natural fibers into polymers could improve some desired properties. However, less attention has been paid to the incorporation of natural fibers to form elastomeric composites [21-30]. These composites exhibit combined behavior of the soft, elastic rubber matrix, and the stiff strong fibrous reinforcement. Thus, these fillers or reinforcement aids are added to rubber formulations to optimize properties. It is well known that the wheat husk fibers (WHFs) are regarded as an agricultural waste that suggested important low-cost and environmental friendly filler derived from a 
TABLE 1: Chemical composition of wheat husk fibers (WHFs).

\begin{tabular}{lc}
\hline Composition & $\%$ \\
\hline Lignin & 16.4 \\
Cellulose & 30.5 \\
Hemicellulose & 28.9 \\
Ash content & $11.2-6.6$ \\
Others & 2.4 \\
\hline
\end{tabular}

renewable source. Therefore, WHFs have fascinating source that is still under careful study and recent development should provide a variety of products where no serious attempt has been made till now.

In this article, attempts are introduced firstly to estimate the effect of fiber size on the interfacial adhesion between WHF of constant concentration (30 phr) and the EPDM matrix. Secondly, the effect of fiber loading on the interfacial adhesion between fibers of wheat husk and EPDM matrix is evaluated. Oscillating disk rheometric analysis (cure meter) and thermogravimetric analysis (TGA and DTGA) as well as swelling measurements and tensile properties of the composites are studied.

\section{Experimental}

2.1. Materials. Wheat husks were obtained from agricultural areas (Beni-Suef, Upper Egypt). Before use, the wheat husks were thoroughly washed several times with tap water followed by three times with deionized water to remove any adhering undesired soil, clay, and dust and finally dried at $102 \pm 2^{\circ} \mathrm{C}$ overnight. The dried husks were grounded mechanically in rotary cutting mill $(10,000 \mathrm{rpm})$ to the range $2-3.5 \mathrm{~mm}$ and then sieved automatically into classification according to their lengths. The investigated fiber lengths were short $(<125 \mu \mathrm{m})$; SW, medium $(125-250 \mu \mathrm{m})$; MW, high (250-500 $\mu \mathrm{m})$; and HW. The chemical composition of the used wheat husk fibers is represented in Table 1.

Ethylene-propylene-diene terpolymer (EPDM) was E/P ratio, $57 / 43$ with specific gravity $0.87-0.89 \mathrm{gm} / \mathrm{cm}^{3}$ that supplied from Uniroyal Chemical Co., Inc, Naugatuck, USA. Paraffin wax was used with molecular weight $340-430$ and wide melting point $35-75^{\circ} \mathrm{C}$, while other standard rubber compounding ingredients such as stearic acid, zinc oxide, and sulfur, that are supplied by Transport and Engineering Company, TRANCO, Alexandria, Egypt, were of commercial grades and used without further purification. The organic solvent used for swelling measurements was chloroform; it has a density of $1.49 \mathrm{gm} / \mathrm{cm}^{3}$.

2.2. Sample Preparation. The formulations of the mixes are given in Table 2. The composite materials were prepared in a two-roll laboratory mill $(150 \mathrm{~mm} \times 300 \mathrm{~mm})$ that is maintained at nearly $50^{\circ} \mathrm{C}$, as described by the American Society for Testing and Materials ASTM D3184-89. The nip gap, mill/roll speed ratio, and number of passes were kept the same for all mixes. The samples were milled for sufficient time to disperse the fibers in the matrix at a mill
TABLE 2: Base formulation of WHFEPDM composites

\begin{tabular}{|c|c|c|c|c|c|c|c|}
\hline $\begin{array}{l}\text { Ingredients } \\
\text { (phr) }\end{array}$ & $\mathrm{MW}_{0}$ & $\mathrm{MW}_{15}$ & $\mathrm{MW}_{30}$ & $\mathrm{MW}_{40}$ & $\mathrm{MW}_{50}$ & $\mathrm{SW}_{30}$ & $\mathrm{HW}_{30}$ \\
\hline EPDM & & & & 100 & & & \\
\hline Zinc Oxide & & & & 5 & & & \\
\hline Stearic acid & & & & 1 & & & \\
\hline $\begin{array}{l}\operatorname{HAF}^{a}(\mathrm{~N}- \\
330)\end{array}$ & & & & 30 & & & \\
\hline Paraffin & & & & 5 & & & \\
\hline $\mathrm{WHF}^{\mathrm{b}}$ & 0 & 15 & 30 & 40 & 50 & 30 & 30 \\
\hline MBTS $^{c}$ & & & & 1 & & & \\
\hline $\mathrm{P} \beta \mathrm{N}^{\mathrm{d}}$ & & & & 1 & & & \\
\hline Resin & & & & 5 & & & \\
\hline Sulfur & & & & 2 & & & \\
\hline Length, $\mu \mathrm{m}$ & & & $125-250$ & & & $<125$ & $\begin{array}{c}250- \\
500\end{array}$ \\
\hline
\end{tabular}

${ }^{a}$ high abrasion furnace black, ${ }^{b}$ wheat husk fibers, ${ }^{c}$ dibenthiazyl disulfide, ${ }^{\mathrm{d}}$ phenyl- $\beta$-naphthylamine.

opening of $1.25 \mathrm{~mm}$. The WHFs were incorporated at the end of the mixing process and taking into consideration the flow direction of the compound to ensure that the majority of the fibers are in the same direction. Rubber mixes were conditioned at nearly $25^{\circ} \mathrm{C}$ for $24 \mathrm{~h}$ prior to cure assessment on a Monsanto Oscillating Disc Rheometer-100 (ODR-100) according to ASTM D1646. The vulcanization was carried out in a hydraulic press under a pressure of about $4 \mathrm{MPa}$, $150^{\circ} \mathrm{C}$ for the EPDM compounds and according to the optimum cure time obtained from rheometer data.

2.3. Characterization. Curing properties were measured in a Monsanto ODR-100 rheometer at a temperature of $150^{\circ} \mathrm{C}$ (ASTM D1646 and D2084). The compounds were cured according to the obtained respective cure times [31, 32]. Swelling test (ASTM D471) was performed on a uniform circular cut from the compression-molded rubber samples with $5 \mathrm{~mm}$ diameter and $2 \mathrm{~mm}$ thick by the immersion/gain method $[33,34]$ in pure chloroform at room temperature for two days to allow the swelling to reach diffusion equilibrium. Dumbbell-shape cutter was employed to punch out the tensile specimens from a $2 \mathrm{~mm}$ vulcanized composite sheets and according to the fiber orientations (longitudinal-transverse). Tensile measurements (ASTM D412-98a) were carried out at a crosshead speed of $50 \mathrm{~mm} / \mathrm{min}$ in a Zwick 1425 tensile testing machine. The tensile strength, $\sigma_{y}$, and ultimate elongation, $E_{b} \%$, were determined at room temperature of the examined samples [21, 23-26, 35].

Thermogravimetric analysis (TGA) is one of the thermal analysis techniques used to measure the mass change, thermal decomposition, and thermal stability of composite materials [36-39].

\section{Results and Discussions}

3.1. Vulcanization Behavior. It is well known that the increase in torque is due to either the crosslinking of the rubber or 
the presence of fibers, while leveling off is an indication of the completion of curing. Data of the cure characteristics at different concentrations of WHF-EPDM are represented in Table 3. The increase in the torque values from the minimum " $M_{L}$ " to the maximum " $M_{H}$ " indicates the increase in the stiffness of the fiber-reinforced materials. It is also shown that the maximum torque of $\mathrm{HW}$ has higher values than the rest of composites due to either the improvement in filler dispersion of the higher fiber length employed or the cure enhancement depending on the type of the elastomer/accelerator system employed [31, 32, 40, 41].

Generally, the results seemed to be dependent mainly on the rubber matrix where the increase in fiber concentration in EPDM mixes does not have a considerable effect on the cure time and scorch time, that is, the rubber phase plays a crucial role in the performance of based natural fiber polymer composites [31].

3.2. Effect of Fiber Length on the Mechanical Properties. The tensile strength and elongation at break values of EPDM composites containing a constant amount (30 phr) of WHF at the different lengths (SW, MW, HW) are shown in Figure 1, respectively.

It exhibited that the MW samples of medium fiber length $(125-250 \mu \mathrm{m})$ in both longitudinal and transverse directions have slightly higher values than other specimens of SW of short length $(<125 \mu \mathrm{m})$ and HW of high length $(250-500 \mu \mathrm{m})$ for the measured parameters due to both better and uniform dispersion of the fibers in the EPDM matrix. while HW sample shows a slightly lower value of tensile strength either due to its relatively higher aspect ratio than other samples SW and MW or its higher degree of lignin on its surface that has the tendency to agglomerate through the formation of hydrogen bonding, that is, contains polar hydroxyl groups $[15,16]$. Thus, with increasing the hydrogen bonding between the fiber surfaces, the area of contact with the EPDM matrix is lowered. However Klason et al. [21] stated that the aspect ratio of lignocellulosic fibers did not necessarily result in the improvement of the strength of a composite, especially if there was widespread fiber agglomeration in the rubber matrix. Also, the reduction in elongation at break for HW may be contributed by the decreased deformability of rigid interface between the filler and the rubber matrix.

3.3. Effect of Fiber Loading on the Mechanical Properties. The behavior of composites of medium length (MW) containing $0,15,30,40$, and $50 \mathrm{phr}$ of WHF on the tensile strength is shown in Figure 2(a). The results show that the tensile strength decreases as the percentage of filler is increased. Similar results have been observed by several workers [23, 35]. It means that WHFs tend to cling together in bundles and resist dispersion of the individual fibers as fiber content increases. These indicate the lack of adhesion between the fibers and rubber matrix, a major reason for the poor tensile strength up to $30 \mathrm{phr}$ in both directions. But the amount

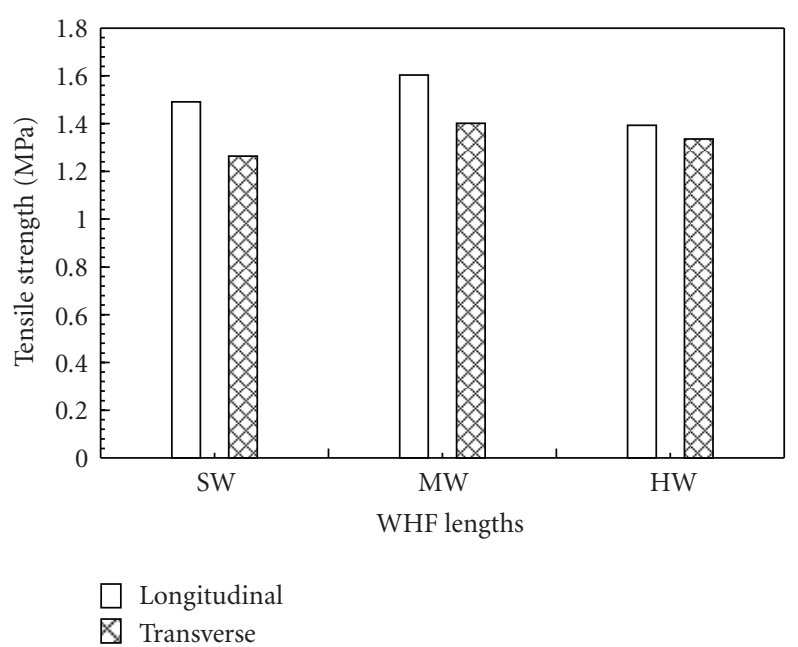

(a)

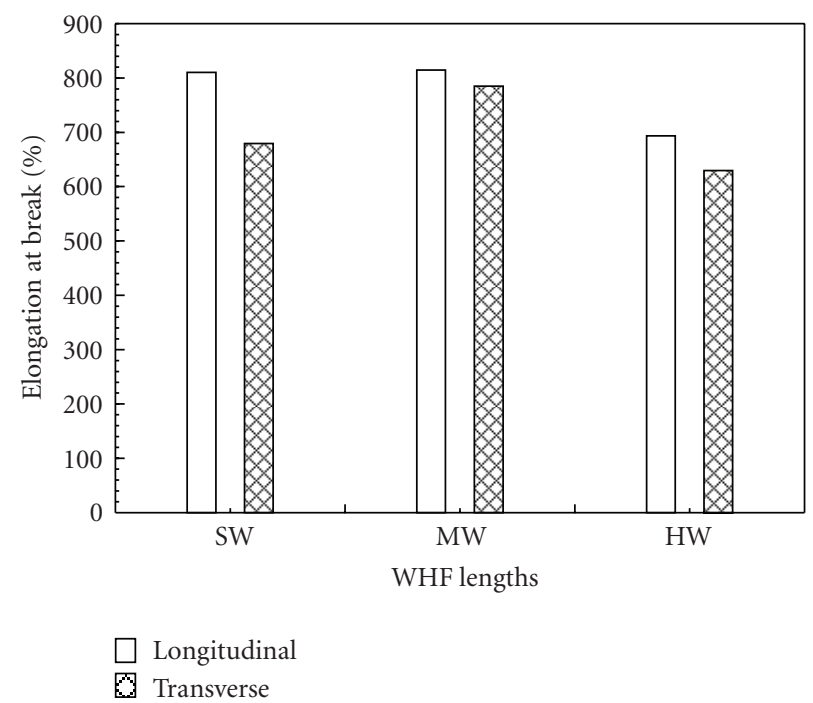

(b)

Figure 1: (a) Tensile strength and (b) elongation at Break,\%, of wheat husk fibers-(WHFs) filled EPDM mixtures at different lengths.

of fibers is sufficient to restrain the matrix after $40 \mathrm{phr}$, the stress distribution will be uniform, and therefore the fibers start reinforcing the matrix. A similar trend was reported by Murty and De [24], Setua and De [25], and Dzyura [26].

The elongation at break, $\varepsilon_{b} \%$, of EPDM composites increases with increasing WHF loading up to a certain concentration $(>30 \mathrm{phr})$ as shown in Figure 2(b). It means that at more filler loading, $\varepsilon_{b} \%$, is decreased with increasing filler loading where a higher restriction to molecular motion of the macromolecules is expected, and so WHF tends to impose extra resistance to flow and lead to lower resistance to break [23]. As elongation is reciprocal to the stiffness of a material $[42,43]$, the results show that the fiber imparts a greater stiffening effect than that of unfilled one. 
TABLE 3: Vulcanization characteristics of WHF-EPDM composites.

\begin{tabular}{|c|c|c|c|c|c|c|}
\hline Mix & $M_{H}(\mathrm{dNm})$ & $M_{L}(\mathrm{dNm})$ & $M_{H}-M_{I}(\mathrm{dNm})$ & $T_{C 90}(\min )$ & $T_{S I}(\min )$ & CRI $\left(\min ^{-1}\right)$ \\
\hline $\mathrm{MW}_{0}$ & 77 & 8.4 & 68.6 & 19.70 & 3.25 & 6.08 \\
\hline $\mathrm{MW}_{15}$ & 78.9 & 9.0 & 69.9 & 20.75 & 2.33 & 5.43 \\
\hline $\mathrm{MW}_{30}$ & 78.9 & 10.9 & 68.0 & 20.25 & 2.73 & 5.56 \\
\hline $\mathrm{MW}_{40}$ & 77 & 10 & 67.0 & 18.83 & 1.85 & 5.89 \\
\hline $\mathrm{MW}_{50}$ & 77.8 & 12.9 & 64.9 & 20.3 & 2.26 & 5.54 \\
\hline $\mathrm{HW}_{30}$ & 85.9 & 11.2 & 74.7 & 19.60 & 2.15 & 5.73 \\
\hline $\mathrm{MW}_{30}$ & 78.9 & 10.9 & 68.0 & 20.25 & 2.73 & 5.56 \\
\hline $\mathrm{SW}_{30}$ & 77.8 & 10.2 & 67.6 & 20.00 & 2.13 & 5.59 \\
\hline
\end{tabular}

Cure time $=t_{\mathrm{C} 90}$, Scorch time $=t_{\mathrm{S} 2}$, Cure Rate Index $=\mathrm{CRI}=100 /\left(T_{\mathrm{C} 90}-T_{\mathrm{S} 2}\right)$.

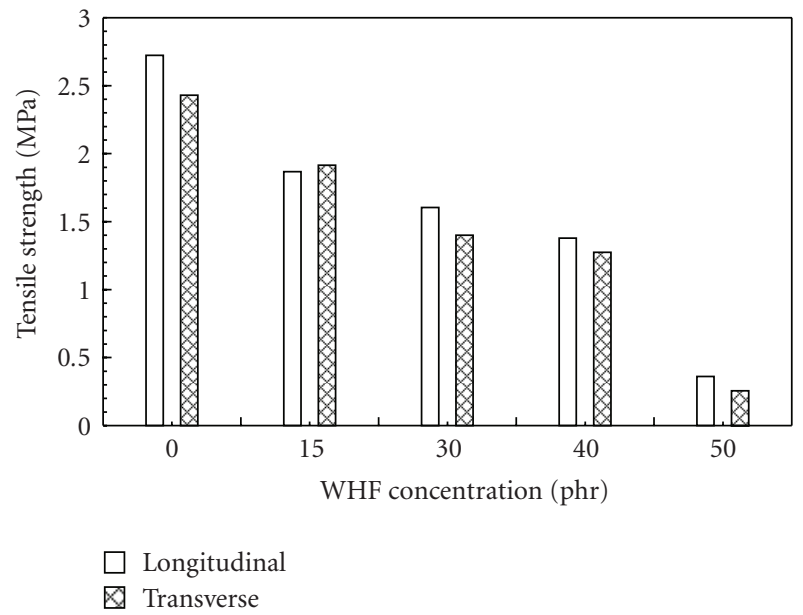

(a)

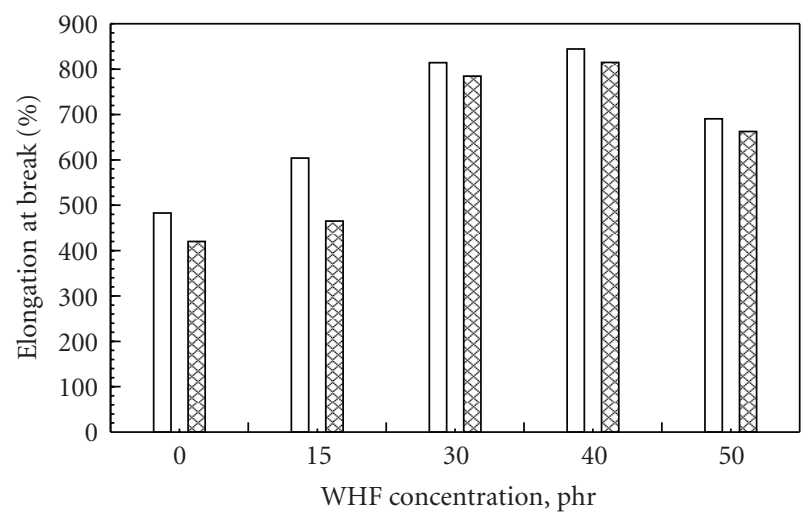

$\square$ Longitudinal

冈 Transverse

(b)

Figure 2: (a) Tensile strength and (b) elongation at Break, \%, at different concentrations of WHF-filled EPDM composites.

3.4. Effect of Fiber Loading on the Swelling Measurements. Several articles have studied the swelling characteristics of filled rubber vulcanizates in a wide range of solvents $[33,34]$. At equilibrium the amount of swelling was treated according

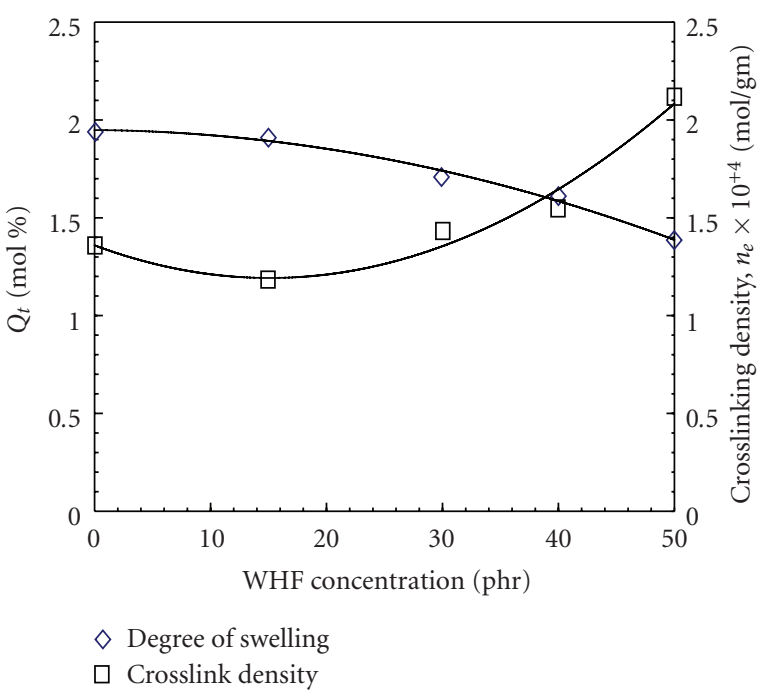

FIGURE 3: Variation of the degree of swelling and crosslinking density as a function of WHF concentrations filled EPDM vulcanizates.

to the Flory-Rehner theory [44] for the swelling of a rubbery polymer:

$$
\ln \left(1-V_{r}\right)+V_{r}+\chi V_{r}^{2}+V_{c} V_{1}\left(v_{r}^{1 / 3}-\frac{V_{r}}{2}\right) V_{0}=0,
$$

where $V_{r}$ is the volume fraction of rubber after swelling, $\chi$ is the polymer-solvent interaction parameter, $V_{c}$ is the number of "moles" of effective network chain in the initial or unswollen volume $V_{0}$, and $V_{1}$ is the molar volume of the solvent.

The degree of swelling and crosslinking density as a function of WHF loading are represented in Figure 3. The uptake solvent, $Q_{t}(\mathrm{~mol} \%)$, values are decreased, while the crosslinking density, $v_{e}$, values are increased with increasing the WHF concentration in the compound. This is because the chain entanglement increases as the WHF increases, thereby, decreasing the solvent uptake.

The degree of restriction exerted by the reinforcing filler allows an equation of the form given by Kraus [32-34]:

$$
\frac{V_{r o}}{V_{r f}}=1-\frac{\left[3 c\left(1-V_{r o}\right)+V_{r o}-1\right]}{[\phi /(1-\phi)]},
$$


TABLE 4: Volume fraction of EPDM due to swelling in Chloroform.

\begin{tabular}{lccc}
\hline Mix & $V_{I}$ & $V_{F}$ & $V_{T}$ \\
\hline $\mathrm{MW}_{0}$ & 0.6666 & 0.41897 & 0.37154 \\
$\mathrm{MW}_{15}$ & 0.6060 & 0.42364 & 0.30092 \\
$\mathrm{MW}_{30}$ & 0.5555 & 0.44995 & 0.19000 \\
$\mathrm{MW}_{40}$ & 0.5263 & 0.46628 & 0.11404 \\
$\mathrm{MW}_{50}$ & 0.5000 & 0.49908 & 0.00182 \\
\hline
\end{tabular}

where $V_{r o}$ is the volume fraction of rubber in the unfilled vulcanizates, $V_{r f}$ is the volume fraction of rubber in the filled vulcanizates, $\phi$ is the volume fraction of the filler, and $c$ is the constant characteristic of the filler which indicates the degree of adhesion [22-30].

The interfacial adhesion between fiber and rubber is estimated from the values of the volume fraction of EPDM in the dry $\left(V_{I}\right)$, swollen $\left(V_{F}\right)$, samples and $V_{T}\left(=V_{I}-V_{F} / V_{I}\right)$ of the WHF-EPDM mixes and is represented in Table 4.

Composites containing higher contents of WHF have substantially lower $V_{T}$ values than those without filler. Das [22] found that with improved adhesion between fiber and rubber, the factor $V_{T}$ decreased by more than 0.04 units. It means that the higher loading compound would exhibit high resistance to swelling, compared with the unfilled one. Consequently, $V_{F}$ would have a relatively higher value and $V_{T}$ would have a relatively lower value. On the other hand, if bonding is poor, $V_{F}$ will be relatively low, resulting in a high $V_{T}$ value. As the fiber loading increases, the amount of penetrated solvent at equilibrium swelling is decreased. This is due to the increased hindrance exerted by the fiber at higher loading.

\subsection{Effect of Fiber Loading on the Thermal Properties.} Thermogravimetric analysis (TGA) is used in studying the kinetics of decomposition, which provides an insight into the thermal stability of polymeric materials. A great interest is achieved by adding a new dimension to TGA analysis by the ability to record the first derivative of the weight loss, that is, the DTGA [36]. It is well known that there are many proposed methods to calculate the kinetic parameters of decomposition [36-38]. Hence, the reported values are depending not only on the experimental conditions but also on the mathematical treatment of the data [39].

Figure 4 shows the thermal degradation patterns of WHF, EPDM, and WHF-EPDM vulcanizates, where the TGADTGA curves show primarily their weight-loss \% at nitrogen medium and over the temperature range $30-600^{\circ} \mathrm{C}$.

Both of the raw husk fibers and the EPDM vulcanizates $\left(\mathrm{MW}_{0}\right)$ are characterized by a single degradation step. Here the initial minor weight-loss $\%$ at around $180-200^{\circ} \mathrm{C}$ is due to the presence of volatile matter such as stearic acid [45]. The rate of weight-loss \% changes when temperatures are deduced from TGA curves and represented in Table 5, that is, WHF can be understood through their thermal decomposition by heating process above $216^{\circ} \mathrm{C}$. Hence, the incorporation of WHF in the EPDM matrix introduces a more effective property that means improving the thermal

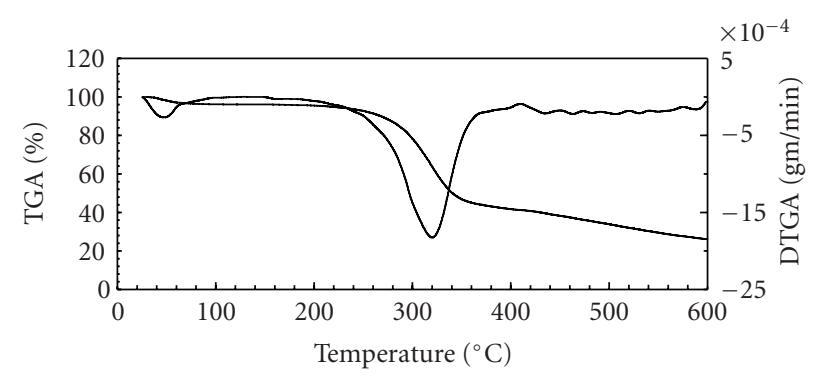

(a)

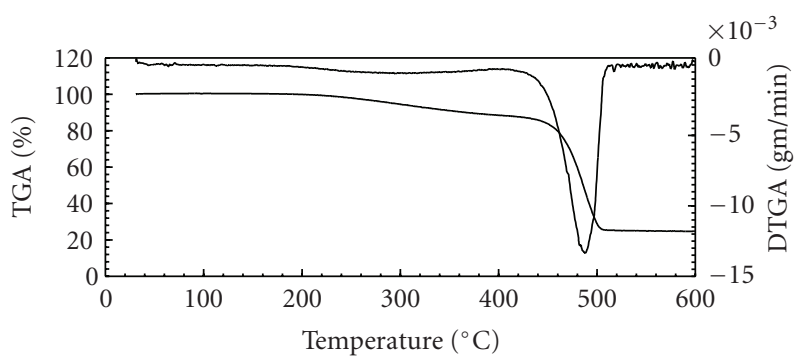

(b)

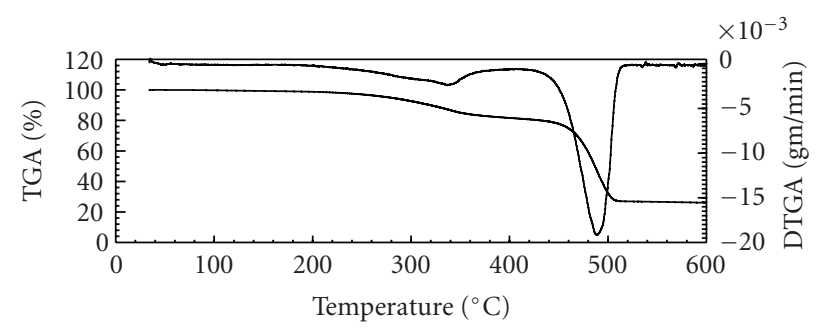

(c)

Figure 4: The TGA-DTGA curves of (a) raw WHF, (b) EPDM vulcanizate and (c) sample $\mathrm{MW}_{30}$.

stability. Also, the DTGA curve of EPDM vulcanizates shows a sharp peak indicating that the rate of decomposition is faster compared to that of WHF-EPDM vulcanizates samples.

Further analysis of the thermograms of the WHF-EPDM vulcanizates is given in Table 6, where it shows that the first degradation steps of the vulcanizates are controlled mainly by the husk fiber and confirmed by the TGA-DTGA curves (cf., Figure 4).

The incorporation of WHF in the EPDM matrix vulcanizates primarily decreased the maximum rate of decomposition of the second degradation step, $T_{m 2}$, relative to the unfilled vulcanizates $\mathrm{MW}_{0}\left(486^{\circ} \mathrm{C}\right)$ as shown in Figure 5.

However, the increase in husk fiber loading increased the rate of decomposition in the first degradation step, $T_{m 1}$, from $316.54^{\circ} \mathrm{C}$ at $\mathrm{MW}_{15} . T_{m 1}$, and $T_{m 2}$ show maximum values for the mix $\mathrm{MW}_{30}$ at 341 and $489.6{ }^{\circ} \mathrm{C}$, respectively, indicating the presence of WHF optimum concentration. Meanwhile, both WHF and EPDM controlled the step $T_{m 2}$ where they occurred in the temperature corresponding to the raw rubber.

Finally, the residue at the end of the degradation is found slightly higher up to the optimum concentration of 
TABLE 5: Decomposition temperatures of WHF, EPDM, and WHF-EPDM vulcanizates at various weight-loss \%.

\begin{tabular}{|c|c|c|c|c|c|c|}
\hline Weight Loss, \% & WHF $\left({ }^{\circ} \mathrm{C}\right)$ & $\mathrm{MW}_{0}\left({ }^{\circ} \mathrm{C}\right)$ & $\mathrm{MW}_{15}\left({ }^{\circ} \mathrm{C}\right)$ & $\mathrm{MW}_{30}\left({ }^{\circ} \mathrm{C}\right)$ & $\mathrm{MW}_{40}\left({ }^{\circ} \mathrm{C}\right)$ & $\mathrm{MW}_{50}\left({ }^{\circ} \mathrm{C}\right)$ \\
\hline 5 & 216.4 & 293.0 & 273.3 & 278.5 & 267.0 & 267.1 \\
\hline 10 & 267.0 & 366.6 & 319.3 & 319.8 & 302.9 & 302.8 \\
\hline 20 & 296.8 & 459.6 & 447.3 & 431.9 & 385.2 & 366.5 \\
\hline 30 & 312.0 & 472.5 & 466.9 & 468.5 & 461.5 & 462.3 \\
\hline 40 & 324.5 & 479.8 & 475.9 & 479.5 & 473.7 & 475.9 \\
\hline 50 & 340.5 & 486.0 & 482.9 & 486.9 & 481.5 & 484.4 \\
\hline 60 & 430.4 & 492.1 & 488.6 & 493.9 & 488.9 & 492.0 \\
\hline 70 & 544.5 & 499.0 & 496.8 & 502.7 & 499.0 & 502.5 \\
\hline
\end{tabular}

TABLE 6: Analysis of the thermograms of WHF, EPDM, and WHF-EPDM vulcanizates at the heating rate of $10^{\circ} \mathrm{C} / \mathrm{min}$.

\begin{tabular}{|c|c|c|c|c|c|}
\hline Sample & $T_{m 1},{ }^{\circ} \mathrm{C}$ & $T_{m 2},{ }^{\circ} \mathrm{C}$ & $\Delta w / d t$ at $T_{m 1}(\% \min )$ & $\Delta w / d t$ at $T_{m 2(\% \min )}$ & Wt. Loss (\%) \\
\hline WHF's & 323.3 & - & 10 & - & 73.79 \\
\hline $\mathrm{MW}_{0}$ & - & 486.02 & - & $65 \%$ & 75.25 \\
\hline $\mathrm{MW}_{15}$ & 316.54 & 480.3 & $7 \%$ & $56 \%$ & 75.10 \\
\hline $\mathrm{MW}_{30}$ & 341 & 489.6 & $13 \%$ & $72 \%$ & 73.94 \\
\hline $\mathrm{MW}_{40}$ & 320.08 & 479.71 & $6 \%$ & $29 \%$ & 73.64 \\
\hline $\mathrm{MW}_{50}$ & 325.3 & 483.2 & $11 \%$ & $53 \%$ & 73.01 \\
\hline
\end{tabular}

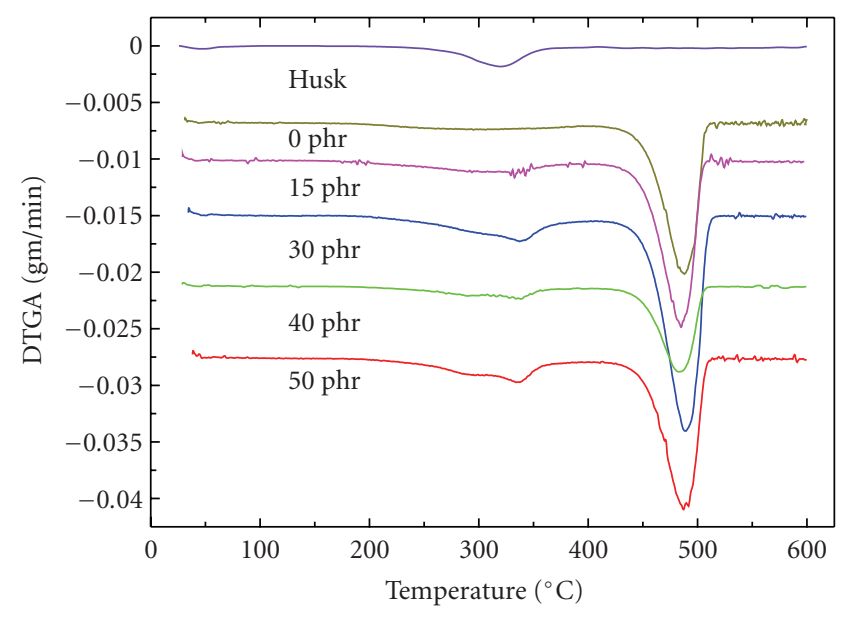

Figure 5: DTGA curves of WHF and WHF-EPDM vulcanizates.

the WHF due to the formation of stable products during vulcanization. It may contribute to the naturally improved adhesion between WHF and EPDM especially for $\mathrm{MW}_{30}$.

\section{Conclusions}

The performance of wheat husk fibers "WHF" as reinforcing filler with different lengths and loading for ethylenepropylene-diene terpolymer (EPDM) is examined. From the foregoing discussions, one may conclude that the optimum length " $\mathrm{MW}_{30}$ " is confirmed by the tensile tests, where these fibers are tend to agglomerate due to the higher degree of lignin on its surface, which in turn increases the hydrogen bonding between the fiber surfaces and lowers the area of contacts.

Furthermore, information about the optimum filler content is detected from the tensile strength values in both directions where the adhesion situation between the WHF up to $30 \mathrm{phr}$ and rubber matrix is lacked. Although with further increase of the filler contents, the stress distribution of the fibers is uniformed and then started to reinforce the matrix, a higher restriction to molecular motion of the macromolecules, the amount of penetrant at equilibrium swelling is decreased, and a thermally stable property is detected from the TGA analysis.

Finally, the reinforcement of the WHF-EPDM composites is acquired due to the naturally improved adhesion between WHF and EPDM during vulcanization especially for $\mathrm{MW}_{30}$.

\section{References}

[1] A. K. Bledzki, J. Izbicka, and J. Gassan, Kunststoffe-UmweltRecycling, Stettin, Poland, 1995.

[2] W. Witting, Kunststoffe in Automobilbau, VDI, Dusseldorf, Germany, 1994.

[3] P. K. Pal, "Jute reinforced plastics: a low cost composite material," Plastics and Rubber Processing and Applications, vol. 4, no. 3, pp. 215-219, 1984.

[4] A. G. Winfield, "Jute reinforced polyester projects for UNIDO/government of India," Plastics and Rubber International, vol. 4, no. 1, pp. 23-28, 1979.

[5] J. Gassan and A. K. Bledzki, "Einfluß von haftvermittlern auf das feuchteverhalten naturfaserverstärkter kunststoffe," Die Angewandte Makromolekulare Chemie, vol. 236, pp. 129-138, 1996. 
[6] A. K. Bledzki and J. Gassan, "Composites reinforced with cellulose based fibres," Progress in Polymer Science, vol. 24, no. 2, pp. 221-274, 1999.

[7] V. G. Geethamma, K. Thomas Mathew, R. Lakshminarayanan, and S. Thomas, "Composite of short coir fibres and natural rubber: effect of chemical modification, loading and orientation of fibre," Polymer, vol. 39, no. 6-7, pp. 1483-1491, 1998.

[8] H. Ishida, Interfacial Phenomena in Polymer, Ceramic and Metal Matrix Composites, Elsevier, New York, NY, USA, 1988.

[9] S.-Y. Lee, H.-S. Yang, H.-J. Kim, C.-S. Jeong, B.-S. Lim, and J.-N. Lee, "Creep behavior and manufacturing parameters of wood flour filled polypropylene composites," Composite Structures, vol. 65, no. 3-4, pp. 459-469, 2004.

[10] H.-S. Kim, H.-S. Yang, H.-J. Kim, and H.-J. Park, "Thermogravimetric analysis of rice husk flour filled thermoplastic polymer composites," Journal of Thermal Analysis and Calorimetry, vol. 76, no. 2, pp. 395-404, 2004.

[11] S. Y. Lee, I. A. Kang, G. H. Doh et al., "Thermal, mechanical and morphological properties of polypropylene/clay/wood flour nanocomposites," Express Polymer Letters, vol. 2, no. 2, pp. 78-87, 2008.

[12] K. Jayaraman, "Manufacturing sisal-polypropylene composites with minimum fibre degradation," Composites Science and Technology, vol. 63, no. 3-4, pp. 367-374, 2003.

[13] D. N. Saheb and J. P. Jog, "Natural fiber polymer composites: a review," Advances in Polymer Technology, vol. 18, no. 4, pp. 351-363, 1999.

[14] A. I. Medalia and G. Kraus, "Reinforcement of elastomers by particulate fillers," in Science and Technology of Rubber, J. E. Mark, B. Erman, and F. R. Eirich, Eds., Academic Press, San Diego, Calif, USA, 2nd edition, 1994.

[15] E. M. Dannenberg, "Filler choices in the rubber industry the incumbents and some new candidates," Elastomerics, vol. 113, no. 12 , pp. 30-50, 1981.

[16] V. Tserki, P. Matzinos, S. Kokkou, and C. Panayiotou, "Novel biodegradable composites based on treated lignocellulosic waste flour as filler-part I: surface chemical modification and characterization of waste flour," Composites Part A, vol. 36, no. 7, pp. 965-974, 2005.

[17] G. Beaucage, S. Rane, D. W. Schaefer, G. Long, and D. Fischer, "Morphology of polyethylene-carbon black composites," Journal of Polymer Science, Part B, vol. 37, no. 11, pp. 1105-1119, 1999.

[18] Z. H. Li, J. Zhang, and S. J. Chen, "Effects of carbon blacks with various structures on vulcanization and reinforcement of filled ethylene-propylene-diene rubber," Express Polymer Letters, vol. 2, no. 10, pp. 695-704, 2008.

[19] D. Qian, E. C. Dickey, R. Andrews, and T. Rantell, "Load transfer and deformation mechanisms in carbon nanotubepolystyrene composites," Applied Physics Letters, vol. 76, no. 20, pp. 2868-2870, 2000.

[20] S. V. Joshi, L. T. Drzal, A. K. Mohanty, and S. Arora, "Are natural fiber composites environmentally superior to glass fiber reinforced composites?" Composites Part A, vol. 35, no. 3, pp. 371-376, 2004.

[21] C. Klason, J. Kubat, and H.-E. Stromvall, "The efficiency of cellulosic fillers in common thermoplastics_-part 1: filling without processing aids or coupling agents," International Journal of Polymeric Materials, vol. 10, no. 3, pp. 159-187, 1984.

[22] B. Das, "Restricted equilibrium swelling - a true measure of adhesion between short fibers and rubber," Journal of Applied Polymer Science, vol. 17, no. 4, pp. 1019-1030, 1973.
[23] H. Ismail, U. S. Ishiaku, A. R. Arinab, and Z. A. Mohd Ishak, "The effect of rice husk ash as a filler for epoxidized natural rubber compounds," International Journal of Polymeric Materials, vol. 36, no. 1-2, pp. 39-51, 1997.

[24] V. M. Murty and S. K. De, "Effect of particulate fillers on short jute fiber-reinforced natural rubber composites," Journal of Applied Polymer Science, vol. 27, no. 12, pp. 4611-4622, 1982.

[25] D. K. Setua and S. K. De, "Short silk fiber reinforced natural rubber composites," Rubber Chemistry and Technology, vol. 56, no. 4, pp. 808-826, 1983.

[26] E. A. Dzyura, "Tensile strength and ultimate elongation of rubber-fibrous compositions," International Journal of Polymeric Materials, vol. 8, no. 2-3, pp. 165-173, 1980.

[27] S. Siriwardena, H. Ismail, and U. S. Ishiaku, "Effect of mixing sequence in the preparation of white rice husk ash filled polypropylene/ethylene-propylene-diene monomer blend," Polymer Testing, vol. 20, no. 1, pp. 105-113, 2001.

[28] S. Siriwardena, H. Ismail, and U. S. Ishiaku, "Mechanical properties and recyclability of thermoplastic elastomer composites of white rice husk ash-ethylene/propylene/diene terpolymerpolypropylene," Plastics, Rubber and Composites, vol. 31, no. 4, pp. 167-176, 2002.

[29] H. Ismail, J. M. Nizam, and H. P. S. Abdul Khalil, "Effect of a compatibilizer on the mechanical properties and mass swell of white rice husk ash filled natural rubber/linear low density polyethylene blends," Polymer Testing, vol. 20, no. 2, pp. 125$133,2001$.

[30] H. Ismail, J. M. Nizam, and H. P. S. Abdul Khalil, "White rice husk ash filled natural rubber/linear low density polyethylene blends," International Journal of Polymeric Materials, vol. 48, no. 4, pp. 461-475, 2001

[31] G. R. Hamed, "Reinforcement of rubber," Rubber Chemistry and Technology, vol. 73, no. 3, pp. 524-533, 2000.

[32] M. S. Sobhy, D. E. El-Nashar, and N. A. Maziad, "Cure characteristics and physicomechanical properties of calcium carbonate reinforcement rubber composites," Egyptian Journal of Solids, vol. 26, no. 2, p. 241, 2003.

[33] L. Ibarra and C. Chamorro, "Short fiber-elastomer composites. Effects of matrix and fiber level on swelling and mechanical and dynamic properties," Journal of Applied Polymer Science, vol. 43, no. 10, pp. 1805-1819, 1991.

[34] M. S. Sobhy, M. M. M. Mahdy, M. A. K. El-Fayoumi, and E. M. Abdel-Bary, "Effect of waste rubber powder in SBR formulations on the swelling of different organic solvents," Polymer Testing, vol. 16, no. 4, pp. 349-362, 1997.

[35] D. M. Bigg, "Mechanical properties of particulate filled polymers," Polymer Composites, vol. 8, no. 2, pp. 115-122, 1987.

[36] D. W. Brazier, "Applications of thermal analytical procedures in the study of elastomers and elastomer systems," Rubber Chemistry and Technology, vol. 53, no. 3, pp. 437-509, 1980.

[37] T. Ozawa, "A new method of analyzing thermogravimetric data," Bulletin of the Chemical Society of Japan, vol. 38, no. 11, pp. 1881-1886, 1965.

[38] W. L. Chang, "Decomposition behavior of polyurethanes via mathematical simulation," Journal of Applied Polymer Science, vol. 53, no. 13, pp. 1759-1769, 1994.

[39] J. Guo and A. C. Lua, "Kinetic study on pyrolysis of extracted oil palm fiber. Isothermal and non-isothermal conditions," Journal of Thermal Analysis and Calorimetry, vol. 59, no. 3, pp. 763-774, 2000.

[40] S. Kohjiya and Y. Ikeda, "Reinforcement of general-purpose grade rubbers by silica generated in situ," Rubber Chemistry and Technology, vol. 73, no. 3, pp. 534-550, 2000. 
[41] M. P. Wagner, Rubber Chemical Technology, vol. 48, p. 271, 1975.

[42] R. G. Raj, B. V. Kokta, and C. Daneault, "Comparative study on the effect of aging on mechanical properties of LLDPE-glass fiber, mica, and wood fiber composites," Journal of Applied Polymer Science, vol. 40, no. 5-6, pp. 645-655, 1990.

[43] R. G. Raj, B. V. Kokta, and C. Daneault, "The use of Isocyanate as a Bonding Agent to Improve the Mechanical Properties of Polyethylene-Wood Fiber Composites," International Journal of Polymeric Materials, vol. 14, p. 223, 1990.

[44] P. J. Flory and J. Rehner Jr., "Statistical mechanics of crosslinked polymer networks I. Rubberlike elasticity," The Journal of Chemical Physics, vol. 11, no. 11, pp. 512-520, 1943.

[45] A. S. Deuri and A. K. Bhowmick, "Ageing of rocket insulator compound based on EPDM," Polymer Degradation and Stability, vol. 16, no. 3, pp. 221-239, 1986. 

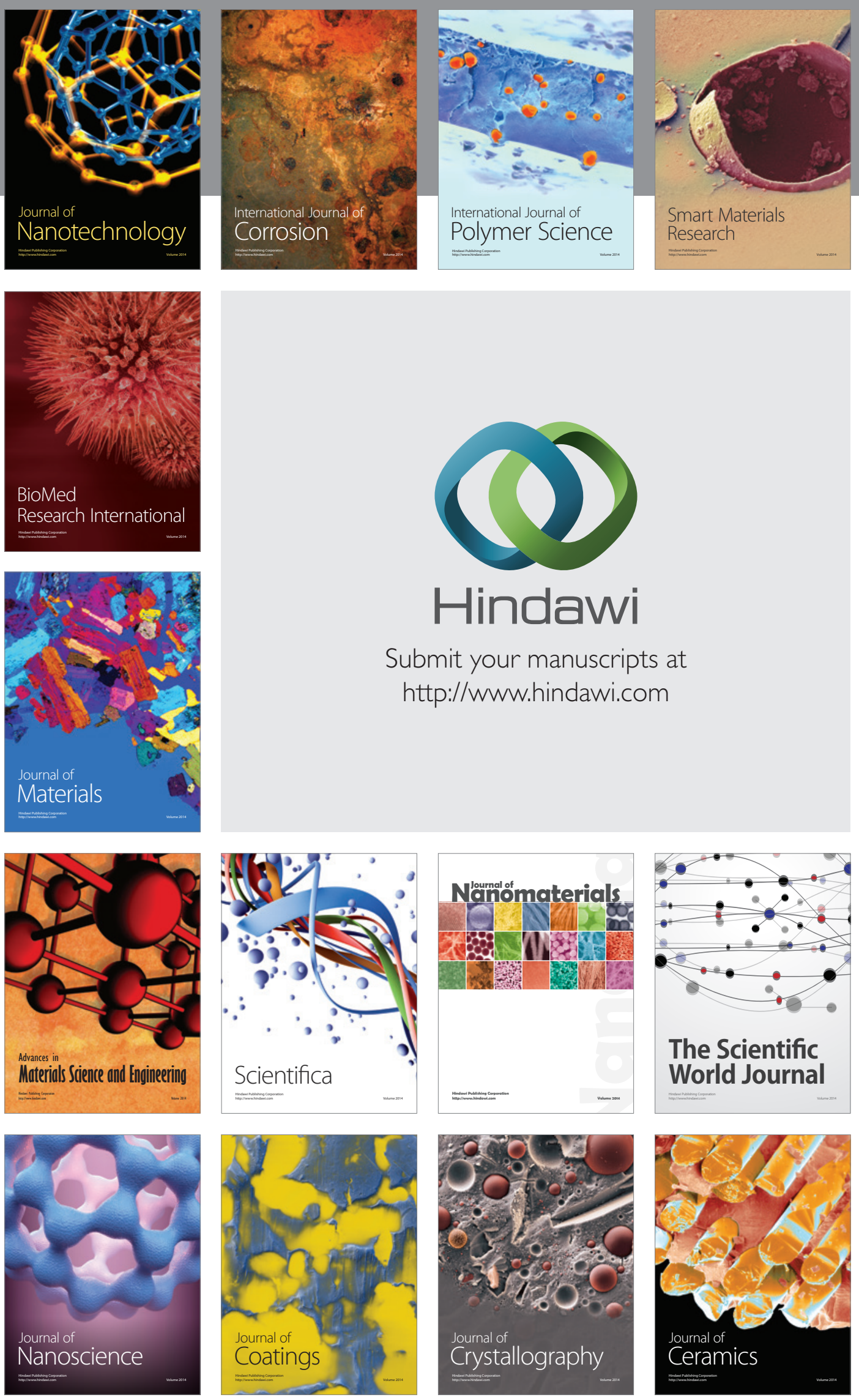

The Scientific World Journal

Submit your manuscripts at

http://www.hindawi.com

\section{World Journal}

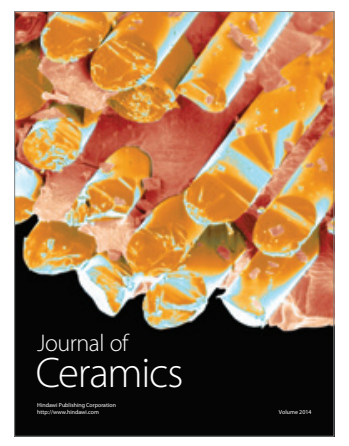

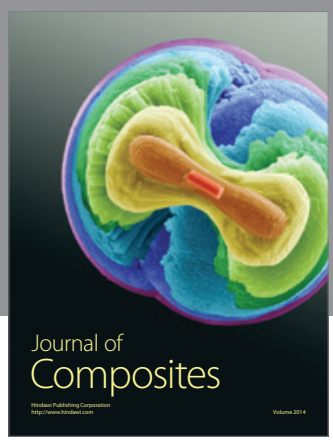
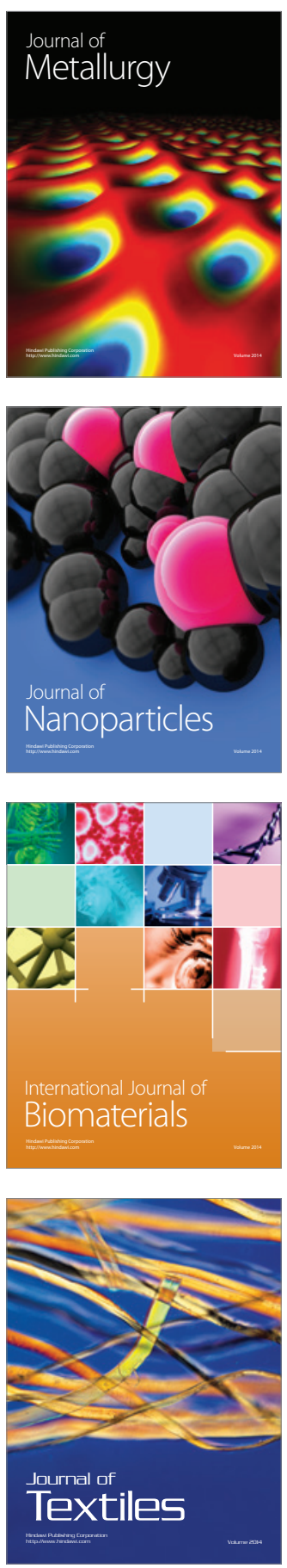